\title{
INVESTIGATING WEATHERING OF BASALTIC MATERIALS IN GALE CRATER, MARS: A COMBINED LABORATORY, MODELING AND TERRESTRIAL FIELD APPROACH (Invited Presentation)
}

\author{
Elisabeth Hausrath, Stephanie J. Ralston, Toluwalope Bamisile, Douglas Ming, Tanya Peretyazhko, \\ Elizabeth Rampe, Seth Gainey
}

Recent observations from Gale Crater, Mars document past aqueous alteration both in the formation of the Stimson sandstone unit, as well as in the formation of altered fractures within that unit.

Geochemical and mineralogical data from Curiosity also suggest Fe-rich amorphous weathering products are present in most samples measured to date. Here we interpret conditions of possible past weathering in Gale Crater using a combination of field, laboratory, and modeling work.

In order to better understand secondary Fe-rich phases on Mars, we are examining formation of weathering products in high Fe and $\mathrm{Mg}$ and low Al serpentine soils in the Klamath Mountains, $\mathrm{CA}$. We have isolated potential weathering products from these soils, and are analyzing them using synchrotron $\mu \mathrm{XRF}$ and $\mu \mathrm{XRD}$ as well as FullPat for a direct comparison to analyses from Gale Crater.

In order to interpret the implications of the persistence of potential secondary Fe-containing phases on Mars, we are also measuring the dissolution rates of the secondary weathering products allophane, $\mathrm{Fe}-$ rich allophane, and hisingerite. Ongoing dissolution experiments of these materials suggest that they dissolve significantly more rapidly than more crystalline secondary minerals with similar chemical compositions.

Finally, to quantify the specific conditions of past aqueous alteration in Gale Crater we are performing reactive transport modeling of a range of possible past environmental conditions. Specifically, we are testing the conditions under which a Stimson unit-like material forms from a parent material similar to Rocknest or Bagnold eolian deposits, and the conditions under which observed altered fracture zones form from a Stimson unit-like parent material. Our modeling results indicate that the formation of the Stimson unit is consistent with leaching of an eolian deposit with a solution of $\mathrm{pH}=6-8$, and that formation of the altered fracture zones is consistent with leaching with a very acidic $(\mathrm{pH}=2-3)$ high sulfate solution containing $\mathrm{Ca}$. These results suggest circumneutral $\mathrm{pH}$ conditions during authigenesis or early diagenesis in the Stimson formation sediments followed by diagenetic alteration by very acidic solutions along fracture zones. 